\title{
What's new in Emergencies? Anesthesia, Surgery and Postoperative Cognition
}

\author{
Ljiljana Gvozdenović 1, 2,", Vesna Pajtić $^{1,2}$, Mišo Dukić \\ ${ }^{1}$ University of Novi Sad, Faculty of Medicine, Novi Sad, Serbia \\ ${ }^{2}$ Clinical Centre of Vojvodina, Novi Sad
}

*Corresponding Author: Ljiljana Gvozdenović, Clinical Center of Vojvodina, Hajduk Veljkova 1, Novi Sad, Republic of Serbia, E-mail: ljiljana.gvozdenovic@kcv.rs

Third millennium, denoted by facts from the World Health Organization and contemporary literature, reveals a new phenomenon of surgical and anesthesiological "nightmare" in form of Post-Operative Cognitive Dysfunction (1-3). Prospective study included 440 patients, male and female, triaged into three groups, with ASA levels I-IV. Additionally, Montreal Cognitive Assessment was performed. Standard laboratory analyses were done and findings recorded. Information about the use of anesthetics and other drugs for anesthesia (ex. anticholinergics), and duration of surgical procedure and anesthesia was statistically evaluated. Criteria for participating in the study: Group I: ASA levels I-IV, undergoing urgent vascular surgical procedure in general or regional anesthesia, within a 6-hour time interval after adequate diagnosis. Group II: patients undergoing major vascular surgical interventions, after 6 hours, but no later than 72 hours of admittance to the Emergency center. Group III: patients did not undergo surgical procedure due to lack of indications and were, therefore, treated conservatively. Twenty participants belonged to the third group of patients. Based on a conciliary decision, they did not have an indication for an urgent surgical procedure and therefore received conservative treatment. These participants did not affect the outcome of the study. Out of the total number of participants, $202(50.5 \%)$ patients were males. 88 (22\%) patients were younger than 40 years of age, $110(27.5 \%)$ patients were between 40 and 60 years of age. Average age of the patients was 55.71 years $( \pm 18,273)$. From the total number of participants involved in the study, $270(67.5 \%)$ patients to
ASA III. Surgical procedure lasted up to 120 minutes in 148 (37\%) patients. In $234(58.5 \%)$ patients duration of anesthesia lasted up to 2 hours, and in $40(10 \%)$ patients up to 3 hours. Interesting is that both first and second group of patients showed a statistically equal number and percent of patients who smoke (208 patients who smoke). Among all patients, 236 (84\%) patients are chronic alcohol users. Additionally, 180 (45\%) patients are chronic users of anxiolytics. Pearson's $\chi^{\wedge} 2$ test shows a statistically significant difference in regard to the use of anticholinergics $\left(\chi^{\wedge} 2=19.220, \mathrm{df}=1\right.$, $\mathrm{p}=0.000, \mathrm{p}<0.05)$. Pearson's $\chi^{\wedge} 2$ test shows a statistically significant difference in regard to blood transfusion, as well $\left(\chi^{\wedge} 2=151.380, \mathrm{df}=1\right.$, $\mathrm{p}=0.000, \mathrm{p}<0.05)$. However, according to Pearson's $\chi^{\wedge} 2$ test, no statistical significance was recorded among patients who consume tobacco and those who do not $\left(\chi^{\wedge} 2=0.320, \mathrm{df}=1\right.$, $\mathrm{p}=0.572, \mathrm{p}>0.05)$. Pearson's $\chi^{\wedge} 2$ test shows no significant difference regarding the use of anxiolytics $\left(\chi^{\wedge} 2=2.000, \mathrm{df}=1, \mathrm{p}=0.157, \mathrm{p}>0.05\right)$, and a statistically significant difference in respect to use of anticholinergics $\left(\chi^{\wedge} 2=19.220\right.$, $\mathrm{df}=1, \mathrm{p}=0.000, \mathrm{p}<0.05)$.

In the study by Mason SE, which involved 255 elderly patients that were postoperatively admitted to the intensive care unit following a major vascularsurgery, development of POCD was two times greater in urgent cases $(\sim 40 \%$ of cases), when compared to elective interventions $(4,5)$.

Our results complement the data given by the World Health Organization and results of similar studies. 


\section{REFERENCES}

[1] Afilalo J, Eisenberg MJ, Morin JF, Bergman H, Monette J, Noiseux N, Perrault LP, Alexander KP, Langlois Y, Dendukuri N, Chamoun P, Kasparian G, Robichaud S, Gharacholou SM, Boivin JF: Gait speed as an incremental predictor of mortality and major morbidity in elderly patients undergoing cardiac surgery. J Am Coll Cardiol 2010, 56:1668-1676.

[2] Ravaglia G, Forti P, Montesi F, Lucicesare A, Pisacane N, Rietti E, Dalmonte E, Bianchin M, Mecocci P: Mild cognitive impairment: Epidemiology and dementia risk in an elderly Italian population. J Am Geriatr Roberts RO, Petersen RC: Subjective complaints in mild cognitive impairment make a difference. Acta Psychiatr Scand 2010; 121:241-2
[3] Geda YE, Roberts RO, Knopman DS, Christianson TJ, Pankratz VS, Ivnik RJ, Boeve BF, Tangalos EG, Petersen RC, Rocca WA: Physical exercise, aging, and mild cognitive impairment: A population-based study. Arch Neurol 2010; 67:80-6

[4] Chan MTV, Cheng BCP, Lee TMC, Gin T CODA Trial Group. BIS-guided anesthesia decreases post-operative delirium and cognitive decline. J Neurosurg Anesthesiol. 2013;25:3342.

[5] Yang J, Choi W, Ko YH, Joe SH, Han C, Kim YK. Bright light therapy as an adjunctive treatment with risperidone in patients with delirium: a randomized, open, parallel group study. Gen Hosp Psychiatry. 2012;34:546-551.

Citation: Ljiljana Gvozdenović, Vesna Pajtić \& Mišo Dukić. What's new in Emergencies? Anesthesia, Surgery and Postoperative Cognition. ARC Journal of Surgery.2017; 3(3): 12-13. doi: dx.doi.org/ 10.20431/2455-572X. 0303004.

Copyright: (C) 2017 Authors. This is an open-access article distributed under the terms of the Creative Commons Attribution License, which permits unrestricted use, distribution, and reproduction in any medium, provided the original author and source are credited. 